\title{
Recombinant Fowlpox-Tyrosinase Vaccine
}

National Cancer Institute

\section{Source}

National Cancer Institute. Recombinant Fowlpox-Tyrosinase Vaccine. NCI Thesaurus.

Code C2807.

A recombinant fowlpox virus vaccine with potential antineoplastic activity. Binding to the melanoma antigen tyrosinase, recombinant fowlpox-tyrosinase vaccine generates cellular immune responses against melanoma cells expressing the tyrosinase antigen; this effect is enhanced by the co-administration of interleukin 2 (IL-2). Fowlpox virus is an attractive vector because its genome is easy to manipulate and it is replication incompetent in mammalian cells. 